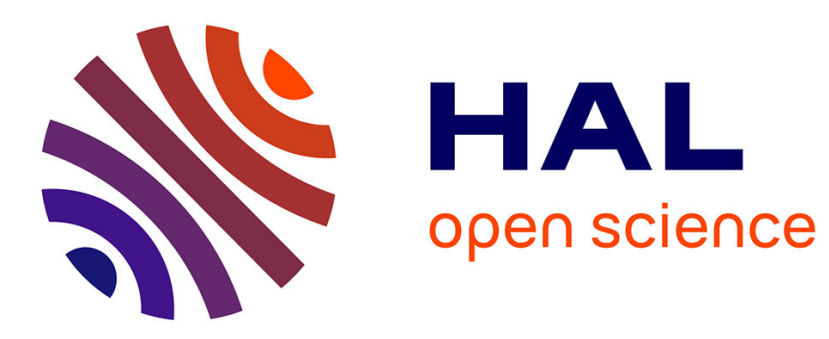

\title{
Email from Nancy Nutsucker
}

Susanna Paasonen

\section{- To cite this version:}

Susanna Paasonen. Email from Nancy Nutsucker. European Journal of Cultural Studies, 2006, 9 (4), pp.403-420. 10.1177/1367549406069065 . hal-00571520

\section{HAL Id: hal-00571520 \\ https://hal.science/hal-00571520}

Submitted on 1 Mar 2011

HAL is a multi-disciplinary open access archive for the deposit and dissemination of scientific research documents, whether they are published or not. The documents may come from teaching and research institutions in France or abroad, or from public or private research centers.
L'archive ouverte pluridisciplinaire HAL, est destinée au dépôt et à la diffusion de documents scientifiques de niveau recherche, publiés ou non, émanant des établissements d'enseignement et de recherche français ou étrangers, des laboratoires publics ou privés. 


\section{Copyright ( 2006 SAGE Publications} London, Thousand Oaks $\mathrm{Ck}$ and New Delhi

Vol g(4) 403-420; $1367-5494$ DOI: $10.1177 / 1367549406069065$ www sagepublications,com

\section{Email from Nancy Nutsucker Representation and gendered address in online pornography}

\section{Susanna Paasonen}

University of Jyväskylä

ABSTRACT This article addresses the representational conventions and gendered forms of address in online pornography through analysis of 366 unsolicited email (spam) messages advertising porn websites.

Combining content description with close reading, it considers the terminology, imagery, narrative elements and points of view employed in advertising commercial heterosexual pornography. The spam advertisements create excessive displays of gender difference. It seems that limited female agency is central, especially in messages advertising reality sites structured by gendered relations of control. Arguing that such displays of control should not be automatically translated as displays of power, this article investigates the representational logic of mainstream pornography as one based on binary differences, juxtapositions and easily recognizable types.

K EYWORDS feminist research, internet research, pornography, representation, spam email

The erosion of identity categories such as gender, age, 'race' or class online has been discussed in internet research since the early 1990 s. Online communications have been defined as a disembodied game or exploration that challenge the very notion of identity (Stone, 1995; Turkle, 1995). This considered, it is perhaps unsurprising that researchers have found identity play in virtual communities, along with different forms of 'cybersex', 'cyborgasms' and 'e-rotics', to be an intriguing and challenging object of study, while mainstream online pornography and its ties to the offline porn industry have been left with relatively little scholarly attention. ${ }^{1}$ Studies of online pornography have focused on freedom of speech and censorship (Ess, 1996), child pornography (Kleinhans, 2004), traffic in women (Hughes, 1999), business and technology (Lane, 2001; Perdue, 2002) and the possibilities provided by the internet to redefine the gendered codes of porn and erotica (Kibby, 2001; Kibby and Costello, 2001; O'Riordan, 2002; Villarejo, 2004; Waskul, 2004). 
The popularity of the internet has brought forth considerable transformations in the production, distribution and consumption of pornography. Together with video and DVD production, the internet has challenged print media in porn publishing. The 37-year-old Penthouse was declared bankrupt in 2003 after its circulation decreased from the five million in its heyday to a mere 650,000 copies. Other magazines have invested in video production and online services: for example, only 20 percent of Hustler's turnover is connected to the printed magazine. The world wide web enables anonymous access to pornography without the need to visit a newspaper stand, special shop or club. Live performances, pornographic images and narratives once available in print and on video are now online. Online distribution has made alternative, independent and amateur productions more accessible than ever before. Given that pornography has an $\$ 11$ billion turnover annually in the United States alone, investments in online content production are hardly marginal in terms of the porn industry or internet usage (Jardin, 2004; Williams, 2004).

Pornography has been considered the first - and perhaps the only profitable form of online content production (Winston, 1998). It has been equally 'avant-garde' in other media. Pornographic images were distributed as photographs and stereoscope images in the 19th century, and in $8 \mathrm{~mm}$ and $35 \mathrm{~mm}$ film, video and Polaroid pictures during the 20 th century. The popularity of video recorders was facilitated by video distribution of porn. The world wide web saw the avalanche of online pornographies in the mid-1990s but pornography was certainly present in the Usenet of the 1980s (Lane, 2001). When Nokia launched its N-Gage gaming mobile phone in 2003, pornographic content was readily downloadable for this platform.

The increasing revenue of the porn industry is connected directly to its increasing visibility in media culture: television, cinema, internet, newspapers, magazines and advertising. Debates on pornography tend to focus on questions of censorship and freedom of speech (especially in the US), whereas the form and content of mainstream pornography is addressed and analyzed more seldomly. This article takes a step in this direction by investigating representational conventions and gendered forms of address in pornographic junk email. The research material consists of 366 unsolicited advertising email messages (spam) archived between October 2002 and February 2004 with screen captures. ${ }^{2}$ Porn spam is part of an avalanche of unsolicited email that comprises an estimated two-thirds of all global email traffic. This material provides one vignette into commercial online pornography. While it is hardly representative of the variety of available porn, it does document daily encounters with online porn.

Spam messages are sent to massive address databases and circulated internationally. They promote a range of products from irresistible mortgage deals to Viagra and Valium, from pills promising to increase penis size to those promising to melt any extra body fat, from incredible dating opportunities to commercial porn sites. The messages in the sample make 
use of HTML (Hypertext Mark-Up Language), making it possible to adjust the background colour, layout and text type of the messages, so that emails resemble the graphic interfaces of the web. The messages are adverts for commercial porn sites and, in many cases, are identical to the 'free tour' pages of the sites themselves. ${ }^{3}$ If the recipient's email client opens the messages in HTML format, images, colours and animated headings open up alongside the text: thus invitations to visit porn sites featuring 'monstrous penises' or 'extreme penetrations' are accompanied by graphic images in full colour.

\section{Marks of gender}

Discussions of pornography as a singular entity are bound to fail. Generalizations conflate genres, practices of production and consumption: as pornography is homogenized into something always already known, queer pornographies and independent productions in particular tend to disappear from view. Being aware of the problems inherent in this, this article aims to be specific about the pornography that the research addresses and the kinds of arguments that can be made on its basis. In order to map the range of representation involved, the process began with a content description of the 366 messages. This meant coding the messages in terms of genre, pictorial elements, acts and terminology employed, as well as the ways of marking the sender and message recipients. This content description provides a general understanding of the material as predominantly mainstream and heterosexual (Table 1); however, this does not equal analysis as such. In order to study the composition and gendered dynamics of individual messages, a close reading of narrative elements, points of view and forms of address has been conducted.

Table 1 Acts depicted

\begin{tabular}{lcc}
\hline Type of act depicted & $\begin{array}{c}\text { No. of depictions } \\
\text { (total }=366)\end{array}$ & $\begin{array}{c}\text { Percentage of all } \\
\text { messages }\end{array}$ \\
\hline Oral sex & 217 & 59 \\
Vaginal penetration & 144 & 39 \\
Girl on girl & 96 & 26 \\
Money shot & 80 & 22 \\
Anal sex & 60 & 16 \\
Group sex & 57 & 16 \\
Bestiality & 8 & 2 \\
BDSM* & 4 & 1 \\
Bisexual sex & 2 & 0.5 \\
Gay sex & 0 & 0 \\
\hline
\end{tabular}

*Bondage/discipline/domination/submission/sadism/masochism 
Table 2 Roles in oral sex

\begin{tabular}{lcc}
\hline Giver/recipient & No. of acts (total=502) & Percentage of all sex acts \\
\hline Female/male & 400 & 79 \\
Female/female & 55 & 11 \\
Male/female & 24 & 5 \\
Female/animal & 8 & 2 \\
Male/male (in bisexual acts) & 5 & 1 \\
Male/transgender & 4 & 1 \\
Transgender/male & 4 & 1 \\
Transgender/transgender & 2 & 0 \\
\hline
\end{tabular}

Oral sex is the most popular of all acts depicted. Within this category, the roles of the 'giver' and 'recipient' are distributed in Table 2.

Depictions of oral sex are often complemented by so-called 'money shots', i.e. male ejaculation targeted at the partner's face, mouth, breast, stomach or back. The sample includes 207 money shots, the majority of which are targeted at a female face (93), mouth (73) and breasts (21). According to Linda Williams' (1989) study of film pornography, money shots were established in the 1970 s as compulsory and highly visible signs of sexual climax that both verify sexual pleasure and culminate the sexual act. Ejaculation is presented also as evidence of female orgasm: female ejaculations were depicted in 6 percent of all money shots in the sample.

Of all figures presented in the messages, 72 percent are female. More specifically, these women are thin $(98 \%)$, young $(92 \%)$, white $(66 \%)$, and have long $(84 \%)$ and blonde $(48 \%)$ hair. Of all the male figures, 65 percent are present only as penises while rest of the male body has been framed out. Although women have been figured as consumers of porn for some decades, the sample does not include advertisements for sites targeted especially at women. As will be argued later in the more detailed discussion of the material, the recipient addressed is typically male and heterosexual, while spaces of female agency tend to be highly limited.

Acts labelled 'lesbian' reproduce the 'girl-on-girl' scenes catering to male consumers and include the possibility of "joining in'. The highly feminine performers of 'girl-on-girl' messages are seen posing together and performing fellatio on plastic dildos while gazing towards the camera. The act implies the penis (or penis-like object) as the assumed primary source of pleasure in lesbian sex while reminding the recipient (or, in narratological terms, the implied reader) of the power of his sexual organ.

Women are described with a wider range of adjectives and nouns than men. Most popular terms for describing women include: 'girl' (31\%), 'slut' (22\%), 'babe' (10\%) and 'lesbian' (7\%); while popular adjectives include: 'hot' (33\%), 'teen' (22\%), 'sexy' (9\%), 'young' (9\%), 'nasty' (4\%), 
'sweet' (3\%) and 'innocent' (3\%). Women are described with nouns in 410 accounts, whereas there are only 4.9 descriptions of men. Their scale is also considerably narrower and homosocial in style: men are referred to as 'guys' (64\%), 'men' (10\%), 'studs' (8\%), 'mates' (6\%), 'buddies' (4\%), 'dudes' $(4 \%)$ and 'brothers' ( $2 \%)$. As a rule, men are not defined with other adjectives than 'horny' except when their penises are described.

Hard/soft, dominant/submissive, aggressive/passive are familiar binary opposites used to schematize masculinity and femininity. Email porn spam makes wide use of this vocabulary in highlighting heterosex as a play of clear-cut differences. The binary gender divide finds resonance in the choice of adjectives. The most popular terms for male genitalia include: 'big' (45\%), 'monster' (17\%), 'huge' (12\%), 'over 12"' (9\%), 'fat' or 'thick' ( $8 \%$ ) and 'massive' (4\%). These are juxtaposed with diminutive terminology for female genitalia: 'tight' (73\%), 'tiny' (11\%), 'little' ( $8 \%$ ) and 'small' $(8 \%)$. This extreme juxtaposition creates a particular vocabulary for heterosex. In addition to general terminology of 'fucking', 'sucking', 'banging' and 'swallowing', it includes verbs such as 'stretch', 'stuff', 'nail', 'punish', 'give hard', 'pound', 'gag', 'torture', 'rip', 'split open', 'choke' and 'dilate'.

This vocabulary reads like a textbook example of morphology of the body that sees female and male bodies - also known as 'opposite sexes' - as complementing each other all the way to their interconnecting genitalia (Richardson, 1996: 7). Such 'heterosexual structuralism' assumes both gender and sexuality as binary structures. Genders are seen as mutually opposing yet interconnected by heterosexual desire (Butler, 1993). In the framework of heterosexual morphology, gender is understood as a fundamental and binary difference separating men and women, while desire stands primarily for desire for otherness. Female desire is defined as difference from male desire, but also as its complementation and opposite. All this implies gendered differences and dynamics of control as central in terms of sexual arousal and gratification (Richardson, 1996). Faithful to the logic of heterosexual structuralism, pornography zooms in on body parts marked as primary signifiers of gender difference, such as genitalia, breasts, buttocks, long hair and red painted lips. Gender differences are defined as primarily sexual and culminate in the presentation of genitalia (Kuhn, 1994[1985]).

The terminology of monstrous penises and tiny vaginas, of the 'stuffing' and 'dilating' employed in the porn spam messages, seems to stretch heterosexual morphology to its extremes. Signs of gender difference are heightened and exaggerated to the degree that heterosexual coitus becomes a near-impossible play of colossal penises and the tiniest of vaginas. In this sense, the material provides abundant possibilities for analyzing the artificiality and compulsive reiteration of gender categories. The messages represents gender as a binary structure in excess, yet these displays of gender 
difference are also advertisements for commercial porn sites that the recipient is desired to pay to visit.

To the degree that the messages feature the highlights of the sites advertised, the logic of excess and overdrive is connected to titillation and potential arousal - the more elaborate the marks of gender and drastic the gender difference, the more hardcore the representation. What the analytically trained eye easily reads against the grain is also a generic example of mainstream hardcore porn. This evokes questions concerning the analytical force of readings that make evident or render visible the heterosexual structuralism at play - after all, this hardly necessitates much revelation (Sedgwick, 2003). Deconsructive readings are always available, but they little explain the obvious titillation of gendered and sexualized relations of control, or their connections to masturbatory practices.

In the realm of spam pornography, men do the chasing and women accept male desire, but there are also exceptions to the rule. In four messages, the scenario of male hunters and female prey is turned around ('Man Hunters', 25 September 2003, 20 January 2004; 'Porn Stud Search', 21 March 2003; 'Tourist Hunter', 12 July 2003). In all four messages, women take men by surprise in everyday settings such as the street or a tax office, and lure them into sexual acts on the spot. The spam adverts for 'Man Hunters' feature two women, defined as 'lethal' and posing with guns. Despite this framing of danger, the lot of their prey is merely to receive oral sex and have intercourse with the woman on top. Thus fantasies of women taking control do not necessitate any significant changes in the pornographic scenario.

The sample includes 11 messages featuring transgender performers and two with bisexual acts, as well as one message in which a woman penetrates a man with a dildo. In these cases, the heteronormative narrative is disrupted by a woman as the holder of the thrusting penis, men engaging in oral sex with each other, and displays of highly feminine transbodies (female to male transsexuals are not part of the diet). The possible confusion caused by the ambivalent transgender body is soothed with the aid of humour:

You have never seen anything this funny. We get these guys and we set them up for the fall. We take them out and let them pretend they are picking up a normal hot chick and even get them to invite her back to our pad. We let them get comfy and when they make their move that's when the fun starts.

This shit will fucking blow your mind, just like it did to those guys who pulled these chicks [sic] panties down and was [sic] shocked to find a cock!!! ('Tranny Surprise', 18 August 2003)

The message lies heavily on comic relief. The possibility of laughing at somebody else (the male protagonist) while still enjoying the action dispels - or at least suspends - explicit queer attraction. Indeed, ads for 'Tranny Surprise', 'Tranny House', 'He-She Club', 'Tranny Zone', 'Sexy 
Transsexuals' and 'Shemale Schlongs' declare that male-to-female transsexuals provide 'the best of both worlds' - a feminine body, male genitalia and an understanding of male sexuality (see Kulick, 1998).

\section{A message just for you}

Pornography addresses its readers in several ways. Forms of address vary from gazes directed at the camera and postures composed for the recipients? eye to direct verbal address. Forms of address are particularly central in email porn spam, as these are simultaneously email messages (with a sender, receiver and subject line) and advertisements (which aim to make the recipient interested enough to click to the service advertised). Of the messages, 55 percent in the sample address users on a general, non-personal level to visit the site or subscribe to it (with calls such as 'click', 'look' or 'join'). Of the others, 31 percent resort to a slightly more personal address ('you can experience, 'you should participate', 'can you imagine') while 14 percent get even more personal ('lusty women are waiting for you', 'command me', 'empty your load on her face'). The target of personal address is male by default, as is evident in references to the recipient's assumed erection and ejaculation when interacting with the site ('spank your monkey on our liveshow slut's face').

The sender is marked as female in the majority of the messages. Slightly less than half of the female sender names are typical female 'porn artist names' such as 'Samantha Cocklovr', 'Shirly Gash', 'Veronica Hotass', 'Jessica Tightho', 'Angelina Whorinto', 'Meg Luvvacock', 'Ashly Gumlicker' or 'Nancy Nutsucker'. These suggest something of the message content before it is even opened. One particularly popular strategy is to mark the subject line as a female invitation or comment: 'Want to get me to spread? Compliment me on my real jugs' ('Pamela Yes', 25 November 2003); 'I suck like a wet vacuum if I can stay rent-free' ('Suzanne Hummer', 12 May 2003), 'My nipples get hard and I get wet down there when Johnny walks in class' ('Joyce Juicycunt', 5 July 2003).

The female narrator is mainly present in the subject line, as the narrator of the message is hardly ever female. The narrator's voice is often invisible or refers to the site, however, it can refer to individual men or male groups performing on the site advertised. Women are the focal point in visual and textual depictions alike, whereas the narrator and implied reader tend to be male. Narrators sketch out the sensory pleasures featured on the site. The advertisement for 'Big Dick Mania' ('Beef Machine', 13 December 2003), addresses the user as one of the boys:

You and I both know little girls like big dicks! They act afraid of the anaconda in our pants but we both know they can't wait to get it inside of their tight little holes! They ride those giant cocks with their sweet little cunts and then wait for the cum when you're done. 
The juxtaposition of 'us' and 'little girls', of 'big' and 'tight' produces clear camps that follow the dictates of heterosexual structuralism. The message also addresses the recipient in a flattering fashion as holder of a 'giant anaconda' which, apparently, all men possess. The recipient is invited to join in a male group (of 'us' and 'we') and this is facilitated further by the display of men as penises only in the message images. In a sense, the recipient can act as an 'extension' of a dismembered yet fully erect member, the collective 'anaconda'. As the male faces remain invisible, their figures stand for 'Joe Averages' into whose shoes viewers may position or imagine themselves.

'Sucking Sonja' (6 December 2003) advertises the site Suck Me Bitch, which invites the recipient to a position of command: 'Make her feel like a real woman. Just say the magic words ... Suck $M e$ Bitch.' The message is toned in shades of brown and beige. Its upper part is dominated by a collage including the slogan and images of eight young women sucking penises and with sperm sprayed on their mouths and faces. The images of women and penises become blended to the degree that the nose of a woman depicted on the left corner appears to grow organically into a penis inserted in another woman's mouth. The introductory text advertises the 'deepthroat action' and 'freakishly messy' money shots with text fonts approximating an edgy, hand-drawn style repeated in the frames drawn around the image and text. Suck Me Bitch is 'all amateur oral action', 'raw \& uncut real home blowjob videos', 'p.o.v. blowjobs' (i.e. fellatio depicted from a male point of view). 'That's right motherfuckers! This is the downright meanest, nastiest site you'll ever find!', 'These girls love to worship cock and it shows', the message enthuses.

The lower part of the message features a gallery of nine photographs and accompanying text. These feature a young and dark-haired woman named Rhiannon, introduced as an 'airport parking slut'. In the largest image Rhiannon looks directly at the camera in semi close-up with her mouth open, sporting a tongue piercing and sperm in her mouth. Next to her face an inserted dialogue bubble declares: 'Mmmm! Tastes great! I want more!' The text box under the image provides a narrative framework for the events depicted in the photographs:

While waiting for her boytoy to arrive, this hot babe was kind enough to assist some poor gentlemen with their so-called locked door. Not only did she assist in openning [sic] the door she gladly release [sic] their stress as well by giving them the best blowjob they have ever had!

In a discussion of depictions of sex acts in cinema, Slavoj Žižek's (1998) argues for the incompatibility of explicit acts and appealing narrative. According to Žižek, ecstatic sexual acts are impossible to represent, since the outsider observer's 'sober' gaze perceives them as amusing and excessive. Something of this kind seems to be at play in the Suck Me Bitch advertisement, that illustrates the fundamental difficulty of representing 
the sexual act, the partners involved or the pleasures derived from it. The exclamation 'Mmmm! Tastes great! I want more!' attributed to Rhiannon is a highly generic - and perhaps, in Žižek's (1998: 25) terms, 'idiotically comical' - expression of pleasure and desire, especially when presented in the context of a threesome in a cramped passenger car.

The difficulty (or, in Žižek's opinion, impossibility) of combining narrative with sex acts 'showing it all' leads to the paradox that the supposedly most spontaneous human activity (sex) is represented in the most codified and formulaic manner (Žižek, 1998). It is well known that pornography reproduces formulaic representational conventions, postures and looks, when marking things out as 'hot' or 'sexy'. Stock characters (such as plumber, horny housewife or cheerleader) and easily recognizable scenes (such as 'the plumber surprises the horny housewife' or 'the cheerleader gives oral sex in a locker room') tend to be equally formulaic. The typical pornographic narrative consists of a series of sketchy scenes surrounding the sex act, providing it with a setting. According to Jennifer Bell (2001), sexual arousal is achieved best through the use of stock characters, since complex and contradictory characters evoking different kinds of emotions tend to decrease and disturb the viewing experience. Stock characters and settings enable quick transition to the sex act itself: "once the scene is set, pornography can get down to real action' (Kuhn, 1994[1985]: 45).

Pornography typifies characters, signs and gestures of arousal and pleasure. Nevertheless, the attraction of porn has been associated with pictorial realism and evidence of sexual pleasure captured by the camera. In this perspective, pornography is seen more as a question of presentation than representation, of boasting the 'authentic presence' of male arousal and orgasm with the aid of the documentary powers of photography and cinematography (Falk, 1993). It seems that both the representational form and strict conventionality of porn are surprisingly easy to bypass. After all, pornography hardly 'records' acts performed for the camera: acts are staged, performed and lighted especially for the cameras situated under, in front of and between the copulating performers. Reflections on authenticity in pornography tend to bypass these obvious technical aspects. Male erection and orgasm, verified by money shots, become guarantees of authenticity in the same vein as pornographic texts themselves.

\section{Porn choreography}

They layout of the 'Suck Me Bitch' advert discussed above-the combination of headers, slogans, collage, links and galleries - is generic to porn spam. The message presents the site's basic concept and newest addition through images and narrative elements. The layout reproduces a familiar spam format.

The text field and money shot image, located in the lower part of the message body, are framed on both sides by four smaller images in chronological 
order. In the first image on the left Rhiannon looks into the camera with a faint smile, while next to her a man in sunglasses gestures with his hands. The second image features a man with a red face and his eyes almost closed. His mouth is open, revealing the lower row of teeth, and he has heavy lines between his eyes. The man's somewhat frightening expression could be one of rage but given the context of the message, it is likely to signify sexual arousal. Based on a stretch of flesh visible in the image, the man seems to be sitting on a backseat with his legs spread. The third image depicts Rhiannon's nude behind with white string bikini pulled down, while in the fourth one Rhiannon is sucking a penis. Her eyes are closed, she holds the penis with her right hand and the man pushes her head lower towards his groin.

On the right, the first image shows Rhiannon smiling at the camera in close-up. Her mouth is open and her teeth are close to the reddish tip of a penis that she is licking. In the next image, Rhiannon looks up to a camera above her. The third image, again, shows Rhiannon on her back with her neck pushed towards the backdoor of the car, and her white shirt pulled up to reveal a breast. Above her, a man is standing with his legs spread and his penis dangling in front of her face. Rhiannon is looking at the penis with raised eyebrows - her neck is tense and the skin of her throat is creased. Together with her tense position, her grin creates an expression of alarm rather than pleasure. Rhiannon's left hand is raised to her throat in a gesture that is both submissive and resistant. The fourth and last image provides closure. In a semi close-up, Rhiannon is shown with her mouth open and her tongue sticking out. On the left, a man is milking sperm into her mouth. The images are fairly low resolution, as is the norm in spam messages. They are toned into grey and brown, colours repeated in the overall layout of the advert.

The message makes evident the basic narrative formula of the site, as well as the spaces of agency available for male and female protagonists. With a few sentences, the text field sketches out a context for the sexual acts specified by the image gallery. The basic act is oral sex, where a woman is servicing several men, and the climax is a money shot targeted at the woman's face and mouth. As in porn more generally, sex acts are not motivated in any particular way: the woman readily agrees, and the men are always willing to have sex.

The point of view in $S u c k M e$ Bitch is decidedly male, as emphasized by the site's title and slogan. The 'narrator' encourages a man to command a woman, named bitch, into giving oral sex, while creating a homosocial framework for the action. The images position the camera into the hands of the male performers but, except for one image, men are visible only as their genitalia, hands and legs.

The 'cock worship' mentioned in the site's content description is evident in the image gallery: licking and sucking male genitalia or pushing a penis down one's throat are depicted as expressions of female desire, 
while the woman remains safely under the men and in male control. The fundamental conceptual difference between a penis and a phallus, emphasized by psychoanalytical theory, appears fluid: a penis is not only a penis, but an always-erect symbol of power and control in front of which women kneel (cf. Black, 2002; Koch, 1993; Williams, 1989). This impression is maintained in images of women looking up to the camera and closing their eyes in enjoyment while men ejaculate on their faces.

\section{Promises of reality and coy plots}

During the past few years, reality has been a central genre in television programming and equally in online pornography. Roughly half of the sample advertises reality sites (such as $S u c k M e$ Bitch) promising glimpses of actual events. The sites assure that their performers are amateur and that the action has not been staged. A documentary sense is achieved by grainy image quality and point-of-view shots that hypothetically could have been recorded by amateurs during their escapades. Generally, the women do not have large silicone implants and the men often lack the large penises otherwise so appreciated in pornography. The adverts depict performers 'hooking up' on streets, hotels or beaches and engaging in casual sexual acts. Scenes are set in mundane spaces such as cars, motel rooms or modestly furnished apartments.

The reality genre bridges the gap between the everyday and the fantasy world of pornography by depicting the most mundane spaces as potential grounds for arousal and copulation. The 'reality effect' supports porn's more general promises of authenticity, of showing everything without any special acting, directing or manipulation of events (cf. Black, 2002). In spite of the reality framing, shaky camerawork and (more or less) amateur performers, the scenarios are poorly motivated on the level of narrative. This necessitates a degree of suspension of disbelief, of playing along with the story.

The reality site concept is often a hoax. Spam introductions suggest that the women performing are unaware of being filmed, let alone of the images ending up on the internet. Women's participation is motivated by ungrounded promises of financial gain, a free place to stay, or help with a residency permit in one message after another. The concept of Captain Stabbing is to lure 'anal virgins' on a ship where several men proceed to have anal and oral sex with them. The description remains fairly identical in all the eight adverts in the sample:

Me and my crew go out to find hot young backdoor virgins and get them aboard

SS Stabbin for some fun in the sun. We sail for the open seas, get what we want and throw the pretty girls out to sea and let them swim back to shore.

In Captain Stabbin, young women are disposable goods whose function is to pleasure men: once the climax is over and recorded in money shots, 
the woman can be disposed. The site concept is humorous, the action is highly staged and the narrative is most obviously a fantasy, but of a sadistic sort. Throwing women overboard is depicted as a narrative closure ensuing male orgasm, as well as a central source of enjoyment. As another advertisement line has it:

These Girls Have No Idea Of What's In Store For Them When They Get On The Captains [sic] Boat. It's All About The Booty And They Get It In The End!

The narration is in the first person singular: the captain and his crew invite users to follow the action (and the 'newest booty') from the male protagonists' perspective. The men are present primarily as 'disembodied penises', often shown in point-of-view camera shots. This widely used representational strategy is also used in Street Blowjobs. Here, the special gimmick is a camera hidden in the male protagonist's spectacles: 'Hot unsuspecting girls lured into sexual acts I film secretly.' The image galleries in the four Street Blowjobs advertisements provide point-of-view shots of foreplay, oral sex, vaginal penetration and money shots recorded as if through the male protagonist's eyes. Consequently, the viewer is offered a position of visual control and, to a degree, that of the (virtual) holder of the penis. As in Captain Stabbin, the site concept is explained to the user, whereas the female performers are said to have no such knowledge.

Point-of-view cameras are, of course, also used in $S u c k M e$ Bitch. The spam message dated 18 January 2004 stars Allura (a 'flea market fuck bunny') as the newest attraction. As in the previous Suck Me Bitch scenario, a young woman is servicing two men with a camera:

We found Allura down at the flea market. It's $2 \mathrm{pm}$ on a tues. afternoon and this bitch is in the food court area, drunk off her ass - can you say LOSER!?

The image gallery features Allura, who appears drunk indeed with drooping eyelids: she is performing fellatio in five images, shows her anus for the camera in one, and exhibits sperm dripping from her mouth in another.

Allura is marked as a drunken loser who hangs out at a flea market food court, drinking beer. She obviously fails to match the criteria of respectability, discussed by Beverley Skeggs (1997) as a marker of class and gender. Not only is Allura consuming goods marked as working class (secondhand products, beer), but is inappropriately and unfemininely drunk early in the afternoon as well as willing to engage in sexual acts with strangers without a hint of chastity. If respectability is, as Skeggs suggests, a key mechanism in othering groups of people, then Allura is certainly othered as a lower-class woman and, as the title of 'flea market fuck bunny' suggests, as used goods. Out of control and out of order, Allura 414. 'has it coming?' 
Pornography represents continuous, abundant and non-committed sex aided by women's assumed insatiability and men's perpetual readiness for sex. As the previous examples illustrate, this does not necessarily imply female agency as anything other than an instrument and mirror of male desire. Women's and men's desire have clearly different structural positions in mainstream heterosexual pornography: women are defined as out of control in their lustiness, as sluts by default, or even as objects of some kind of abuse.

Writing on pornographic magazines, Kaarina Nikunen (1996) critiques the assumption of the viewer as necessarily male, and the women depicted as passive objects. According to Nikunen, this is merely a reading convention that situates women in the realm of the 'chaste look' and detaches them from the influence of porn. Since women have not been defined as sexually active agents, it is difficult to find female agency in pornography. However, the question is one of reading conventions and pornographic images can be read differently by defining women as active subjects in control (Nikunen, 1996). In the sample, women can be seen to enjoy sexual acts and enjoy being positioned as objects of gaze, and such readings are definitely encouraged by the narrative elements. Nevertheless, a more systematic shift of perspective is difficult to achieve. Spaces of female agency are limited on the level of image composition, ways of addressing the user, naming the characters depicted and narrating the flow of events. In fact, it seems that limited female agency is central, especially in messages advertising reality sites: the sites' basic concept is built around gendered relations of control.

Female sexual autonomy is emphasized mainly in advertisements for adult dating. These are also the messages naming women as 'women' or 'dames' rather than 'girls', 'sluts' or 'babes'. On adult dating sites, women are looking for sex partners:

$100 \%$ Horny, 100\% Amateur, 100\% Real. We have every intention of getting you laid. Our female members are motivated by their own sexual needs. They want to fuck and they want to do it now. (EZCheating.com, 4 August 2003)

This focus on female sexual agency is rare in the spam material. However, a hyperlink located at the very bottom of the message body seems to undercut the rhetoric of female sexual autonomy: 'Your next door neighbors by day ... Your sexual fuck slaves by night.' In a sudden shift of narration, women looking for sexual partners are transformed from agents of desire to sexual slaves. Furthermore, the male user is offered the position of master of several willing female slaves.

\section{On control and power}

Pornography is among the most generic of popular genres. Its conventions are slow to change and are recycled with considerable vigor, especially 
in the realm of mainstream commercial heterosexual pornography such as that addressed in this article. With its stock characters, vocabulary, accessories, key acts, gestures and positions, pornography works to define sexual scenarios and body styles as arousing and titillating. This results in a catalogue of representational conventions that are circulated further in advertising, music videos, cinema and gaming.

The stock materials and themes of pornography revolve around relations of control. The roles of the active and passive partner, the hunter and prey, the con and conned are easily recognizable and clear-cut. In the vast majority of messages in the sample, women are the ones under control. These scenarios repeat gendered power relations and code them as erotic. In this sense, the sample does not merely concern the 'titillating' display of sexual acts, nudity, bodily parts or cavities, but also imageries of power and control.

Attention should be paid to both the connections and differences between the concepts of control and power in discussions of pornography, as conflating them is both easy and over-simplifying. All kinds of pornography revolve around scenarios and fantasies of control: the virgin and seducer, the student and teacher, the slave and master reappear in one scenario after another, in straight and queer pornographies alike. This hardly means that all scenarios of control can be translated into reiteration or representation - let alone evidence - of power relations. Doing so leads to a kind of automatism where power is positioned as the self-explanatory outcome of analysis. This, again, does little to explain the representational dynamics of pornography.

In addition to the strict division of male and female positions, porn choreography concerns relations of control articulated in relation to age, 'race', ethnicity, class and nationality. Porn uses types rather than characters and displays acts rather than complex narrative trajectories. All this leads to predictability in terms of settings and story, as well as in normative templates concerning desire and sexual acts. These templates can be altered, elements can be removed and new ones added, texts scripted and styles changed. While templates produce a certain degree of repetition and familiarity, they do not dictate the content or meanings of the text in question. The degree of variation alters, new templates are created and old ones appropriated. Nevertheless, a certain sense of déjà vu is difficult to avoid. Richard Fung's (1991) notion on gay porn - that 'there is such a limited vision of what constitutes the erotic' - certainly applies to the sample of porn spam email in this research.

In examples such as Suck Me Bitch, Street Blowjobs or Captain Stabbin, gendered positions are rigid. Men are in control and on top and invite other men to join in the action. These examples of reality sites display fantasy scenarios that are difficult to draw apart from gendered relations of power: male dominance and female willingness to serve are featured from the point of view of male protagonists and male pleasure. 
The pleasures of popular culture have been of central interest to cultural studies: pleasures of viewing and consumption have been read as political and empowering tactics of everyday life, identity work, negotiation and customization of meaning. Case studies have addressed soap operas, popular music, television and film, while - perhaps for obvious reasons seldom has pornography been included in such explorations. Studying porn necessitates questioning the kinds of scenarios of control and power to which we subscribe while consuming and enjoying products of media culture. Making visible the conditions of viewing pleasure, pornography necessitates a critical reflection of the notion and meaning of pleasure in general.

Addressing the either/or debate that has tended to control feminist discussions on pornography, Lynn Chancer (1998) notes that imageries of control and submission are as real and central as erotic pleasures. A critique of hegemonic heterosexual porn and its choreographies does not foreclose analysis of diverse pleasures derived from pornographic representations. Neither do investigations into commercial sex and traffic in women in any way foreclose reflection on the potential of alternative pornographies. Rather, it is precisely such interconnections and dual visions that help to push debates further.

The quite predictable spam messages from Nancy Nutsucker bear witness to the conventions and influence of mainstream heterosexual porn. They also make evident the need to address the centrality of control and relations of power for pornographic conventions. All this is crucial in the framework of internet research that has tended to emphasize both freedom and play when discussing sexuality online, and to draw online pornographies apart from their offline variations. The scholarly perspective outlined here is not blind towards questions of pleasure, but highly sensitive to their conditions, to the spaces of agency available to Nancy Nutsucker, her colleagues and the implied recipients of her messages.

\section{Notes}

1. JoAnn di Filippo (2000) has studied online porn publishing. Susan Herring and Anna Martinson (2003) have analysed the US portal Sex Tracker through systematic content description. The portal in question aims to provide content for women, men and users identifying themselves as lesbian, gay or bisexual, although the majority of content caters to a heterosexual audience.

2. I have excluded from the sample all doubles, messages using text only, and ones that failed to open. Also, when traveling, I occasionally deleted all spam from my inbox. Given the large amount of doubles and defective image files, the 366 messages represent roughly one-third or one-quarter of all porn spam received in my university email account during the 17 -month period archiving period.

3. The spam messages are not necessarily sent out by the service advertised. It should be noted that 'free tour' materials are adapted and recycled by 
spammers aiming to generate traffic with the aid of links email, links, and pop-ups (Bonik and Schaale, 2005).

4. All quotes are reproduced with their original spelling intact. This includes a liberal use of grammar.

\section{References}

Bell, J.L. (2001) 'Character and Cognition in Modern Pornography', in A. Koivunen and S. Paasonen (eds) Conference Proceedings for Affective Encounters: Rethinking Embodiment in Feminist Media Studies, pp. 36-42. Turku: University of Turku.

Black, J. (2002) The Reality Effect: Film Culture and the Graphic Imperative. New York: Routledge.

Bonik, M. and A. Schaale (2005) The Naked Truth: Internet Eroticism and the Search', Cut-Up Magazine 3(20). [Accessed 4 April 2006: http://www .cutup.com/news/issuedetail.php?sid=4.12\&issue=20]

Butler, J. (1993) Bodies That Matter: On the Discursive Limits of 'Sex'. London: Routledge.

Chancer, L.S. (1998) Reconcilable Differences: Confronting Beauty, Pornography, and the Future of Feminism. Berkeley: University of California Press.

di Filippo, J. (2000) 'Pornography on the Web', in D. Gauntlett (ed.) Web.Studies: Rewiring Media Studies for the Digital Age, pp. 122-9. London: Arnold.

Ess, C. (1996) 'Philosophical Approaches to Pornography, Free Speech, and CMC Cyberspace as Plato's Republic: Or Why This Special Issue?' Computer-Mediated Communication Magazine 3(1). [Accessed 4 April 2006: http://www.december.com/cmc/mag/1996/jan/ed.html]

Falk, P. (1993) 'The Representation of Presence: Outlining the Anti-Aesthetics of Pornography', Theory, Culture \& Society 10(2): 1-42.

Fung, R. (1991) 'Looking for My Penis: The Eroticized Asian in Gay Male Porn', in Bad Object-Choices (ed.) How Do I Look? Queer Film and Video, pp. 145-60. Seattle, WA: Bay Press.

Herring, S. and A. Martinson (2003) 'Representational Bias on Sextracker', paper presented at the Internet Research 4.0: Broadening the Band Conference, Toronto, 16-19 October.

Hughes, D. (1999) 'The Internet and Global Prostitution Industry', in S. Hawthrone and R. Klein (eds) CyberFeminism: Connectivity, Critique \& Creativity, pp. 157-84. Melbourne: Spinifex.

Jardin, X. (2004) 'Life, Liberty and Pursuit of Porn'. Wired News. [Accessed 4. April: http://www.wired.com/news/privacy/0,1848,62343,00.html]

Kibby, M. (2001) 'Women and Sex Entertainment on the Internet: Discourses of Gender and Power', Mots Pluriels 19. [Accessed 4 April 2006: Electronic document, http://www.arts.uwa.edu.au/MotsPluriels/MP1901mk.html]

Kibby, M. and B. Costello (2001) 'Between the Image and the Act: Interactive Sex Entertainment on the Internet', Sexualities: Studies in Culture and Society 4(3): 353-69.

Kleinhans, C. (2004), 'Virtual Child Porn: The Law and the Semiotic of the Image', in P. Church Gibson (ed.) More Dirty Looks: Gender, Pornography and Power (2nd edn), pp. 71-84. London: British Film Institute. 
Koch, G. (1993) 'The Body's Shadow Realm', in P. Church Gibson and

R. Gibson (eds) Dirty Looks: Women, Pornography, Power, pp. 22-45.

London: British Film Institute.

Kuhn, A. (1994[1985]) The Power of the Image: Essays on Representation and

Sexuality. London: Routledge.

Kulick, D. (1998) Travesti: Sex, Gender and Culture among Brazilian

Transgender Prostitutes. Chicago, IL: Chicago University Press.

Lane, F.S., III (2001) Obscene Profits: The Entrepreneurs of Pornography in the Cyber Age. New York: Routledge.

Nikunen, K. (1996) 'Pornokuva ja naisen siveä katse' ['Porn Image and the

Chaste Female Look'], in M. Laiho and I. Ruoho (eds) Naisen naamio, miehen maski: katse ja sukupuoli mediakuvassa [Female Mask, Male Guise:

Look and Gender in Media Images], pp. 33-60. Tampere: KSL.

O'Riordan, K. (2002) 'Windows on the Web: The Female Body and the

Web Camera', in M. Consalvo and S. Paasonen (eds) Women and Everyday

Uses of the Internet: Agency and Identity, pp. 44-61. New York: Peter Lang.

Perdue, L. (2002) EroticaBiz: How Sex Shaped the Internet. New York: Writers

Club Press.

Richardson, D. (1996) 'Heterosexuality and Social Theory', in D. Richardson

(ed.) Theorising Heterosexuality: Telling it Straight, pp. 1-20. Buckingham:

Open University Press.

Sedgwick, E.K. (2003) Touching Feeling: Affect, Pedagogy, Performativity.

Durham, NC: Duke University Press.

Skeggs, B. (1997) Formations of Class and Gender: Becoming Respectable.

London: Sage.

Stone, A.R. (1995) The War of Desire and Technology at the Close of the

Mechanical Age. Cambridge, MA: MIT Press.

Turkle, S. (1995) Life on the Screen: Identity in the Age of the Internet.

New York: Simon \& Schuster.

Villarejo, A. (2004) 'Defycategory.com, or the Place of Categories in

Intermedia', in P. Church Gibson (ed) More Dirty Looks: Gender,

Pornography and Power (2nd edn), pp. 85-91. London: British Film

Institute.

Waskul, D.D. (ed.) (2004) Net.seXXX: Readings on Sex, Pornography, and the

Internet. New York: Peter Lang.

Williams, L. (1989) Hard Core: Power, Pleasure, and the 'Frenzy of the Visible'.

Berkeley: University of California Press.

Williams, L. (2004) 'Porn Studies: Proliferating Pornographies on/Scene: An

Introduction', in L. Williams (ed.) Porn Studies, pp. 1-23. Durham,

NC: Duke University Press.

Winston, B. (1998), Media Technology and Society. A History: From the

Telegraph to the Internet. London: Routledge.

Žižek, S. (1998) 'From Sublime to Ridicule, or, Sexual Act in Cinema',

Lähikuva 4: 19-35. 


\section{Biographical note}

Susanna Paasonen is Assistant Professor of Digital Culture at the University of Jyväskylä, Finland. She is the author of Figures of Fantasy: Internet, Women, and Cyberdiscourse (Peter Lang, 2005), co-editor of Women and Everyday Uses of the Internet: Agency and Identity (Peter Lang, 2002), and is currently coediting a volume on pornography and popular media culture. A D D E ES : Digital Culture, PL 35 (jt), 40014. University of Jyväskylä, Finland. [email: susanna. paasonen@campus.jyu.fi] 